\title{
A political economy model of road pricing
}

\author{
Bruno De Borger and Stef Proost (*)
}

\begin{abstract}
In this paper, we take a political economy approach to study the introduction of urban congestion tolls, using a simple majority voting model. Making users pay for external congestion costs is for an economist an obvious reform, but successful introductions of externality pricing in transport are rare. The two exceptions are London and Stockholm that are characterized by two salient facts. First, the toll revenues were tied to improvements of public transport. Second, although a majority was against road pricing before it was actually introduced, a majority was in favor of the policy reform after its introduction. This paper constructs a model to explain these two aspects. Using a stylized model with car and public transport, we show that it is easier to obtain a majority when the toll revenues are used to subsidize public transport than when they are used for a tax refund. Furthermore, introducing idiosyncratic uncertainty for car substitution costs, we can explain the presence of a majority that is ex ante against road pricing and ex post in favor. The ex ante majority against road pricing also implies that there is no majority for organizing an experiment that would take away the individual uncertainty.
\end{abstract}

\section{Keywords}

Road pricing, acceptability of tolls, policy reform, earmarking of toll revenues, Pigouvian taxes

\section{JEL-codes}

D72, H23, R48

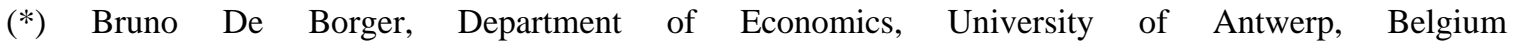
(bruno.deborger@ua.ac.be); Stef Proost, Center for Economic Studies, KULeuven, Belgium (stef.proost@kuleuven.ac.be). We are grateful to FWO-Flanders for financial support. The authors benefited from comments by seminar participants at UCIrvine, Northwestern University transportation center , the Central Planning Bureau (NL) and the ETE group at CES-KULeuven. We are particularly grateful to R.Braeutigam,J. Brueckner, A. Glazer, K.Small and W. Weijschede- v.d. Straaten. 


\section{Introduction}

Although many economists consider the introduction of urban road tolling as efficiency-enhancing, there are only a limited number of cases where urban tolls were actually introduced ${ }^{1}$. Examples include London, Stockholm, Riga and several Norwegian cities (Bergen, Oslo). Many other cities seriously considered road tolls, but their actual implementation turned out to be politically infeasible. In Edinburgh, Birmingham and Manchester, road tolls were opposed by an overwhelming majority when the proposal was put to a vote in local referenda. Although Mayor Bloomberg of New York was strongly in favor of tolling, in 2008 the New York State Assembly ultimately decided not to vote on a proposal to introduce road tolls. In the Netherlands, road pricing has been on the agenda for decades, but implementation has been postponed several times.

Reviewing the experience where pricing was actually implemented -- especially in the best documented cases of London and Stockholm, but also in Bergen and Oslo -one observes two salient facts. First, it seems that in these cities the attitudes towards road tolls substantially changed over time, becoming more favorable after introduction of the tolls. In several instances, there was a clear majority against road pricing before it was actually introduced, but a majority was in favor of the policy reform after its introduction (see, e.g., Schade and Baum (2007); for more details, see Section 2 below). This implies that urban road tolling could only be introduced by politicians that took decisions that ran temporarily against the will of the majority. Second, in all cases of successful introduction of road tolls, the toll revenues were somehow closely tied to subsidies for public transport or to financing improvements of public transport service levels or quality.

In this paper, we take a political economy approach to study the introduction of road tolls, using a simple majority voting model. We use stylized one and two mode models in which voters decide on whether or not to introduce "optimal" road pricing and, if it is introduced, on the allocation of the toll revenues. Two alternative revenue uses are

\footnotetext{
1 There are exceptions to the general view that road tolls are efficient, mainly due to its sizeable implementation costs. For example, Prud'homme and Bocarejo (2005) argue that road pricing is not yet efficient because the transaction and implementation costs are still too large, compared to the gains of reduced congestion.
} 
considered: subsidies to public transportation and a tax refund to all voters. We follow the literature on economic reform (see Fernandez and Rodrik (1991), Jain and Mukand (2003), Ciccone (2004)) and study the political outcomes both in the absence and in the presence of idiosyncratic uncertainty on the costs of switching modes for the initial car users. We show that, although a majority may be in favor of road pricing once the uncertainty is resolved (ex post), uncertainty is likely to imply a negative expected benefit for initial car drivers. Hence, uncertainty increases opposition from existing drivers, and this may easily imply a majority against the introduction of road pricing ex ante. Moreover, we show that it may also generate a majority against a road pricing experiment that would resolve the uncertainty. This suggests that politicians that favor road pricing may have to implement a road pricing experiment without having a referendum on whether to have such experiment.

Our model is deliberately simple and, although it contains no magic recipe for a successful introduction of road pricing, it does help to understand the role of a road pricing experiment and the impact of different revenue uses on the political acceptability of road pricing. The main contribution of this paper is, therefore, that it provides a potential answer to a number of specific questions: (i) why do we observe so few cases of successful implementation of road pricing?; (ii) why are more people against tolling ex ante than after its introduction ex post?; (iii) why is revenue use so closely tied to public transport?

The paper unfolds as follows. In Section 2, we provide some evidence on the implementation of urban road pricing, and we review the relevant transport and political economy literature that may help explain some of the most striking observations. Section 3 sets out a simple majority voting model with only one transport mode to study the attitude of different groups towards urban road tolls. We consider voting outcomes both in the absence of uncertainty and in the presence of idiosyncratic uncertainty about individuals' willingness to pay for road use. Section 4 extends the model to two modes (car and public transport) and introduces a wider choice of recycling strategies, including public transport subsidies. Moreover, it studies the role of people not using any peakperiod transport at all. Section 5 concludes. 


\section{The political economy of implementing road tolls}

In this section, we briefly review the most striking characteristics associated with the recent implementation of road pricing in a number of European cities. We then discuss several strands of literature that may help to understand and explain some of the empirical observations.

\subsection{Implementing road tolls: resistance to reform and change in attitudes}

After the early introduction in Singapore, some form of urban tolling was introduced in Norway (Bergen, Oslo, Trondheim) in the late 80's and early 90's. More recently, tolls were implemented in London (2004) and Stockholm (2008). In all cases, the introduction was combined with substantial improvements in the service frequency and quality of the public transport system. As mentioned in the introduction, introducing urban tolling failed in many other cities across Europe and, more recently, in the US.

Apart from using the revenues mainly for public transport, one is struck by two other remarkable phenomena when reviewing the few cases of successful introduction of pricing. One is that it seems that road pricing has usually been implemented against the will of a majority of voters. The other is that the evidence overwhelmingly suggests that public opinion became much more favorable towards road pricing after its formal introduction.

First, consider the Norwegian experience. In Bergen public opinion moved from strong opposition to almost majoritarian support after introduction of tolls (Larsen (1988), Tretvik (2003)). Similarly, in Oslo the attitude towards the toll ring road changed dramatically over time: before the introduction of pricing, $40 \%$ of the population reported to be very negative; after implementation, this figure declined to 17\% in 1998 (see Schade and Baum (2007)). Moreover, analyzing the situation in Trondheim, Tretvik (2003) reports substantially declining opposition to the tolls after their implementation as well. Second, analogous findings have been reported in London. Transport for London (2004) reports at regular intervals the public attitude on the London congestion toll, introduced in 2003. In late 2002, it was found that $40 \%$ rejected congestion charging, 
while $40 \%$ supported it. After introduction of the charging system in 2003 only $25 \%$ $30 \%$ rejected congestion pricing, whereas $50-60 \%$ indicated they were in favor.

A third and well documented example is Stockholm (see, e.g., Eliasson (2009)). Prior to introduction of the system, there was a congestion pricing trial from January 2006 - July 2006, accompanied by an extension of the public transport system from August 2005 onwards. The decision to have the trial went back to a promise of the Green party -- that was in favor of the trial -- to support a minority government of socialdemocrats in 2002. Although the opposition asked for a referendum before the trial, this was not organized by the majority in power; the reason was that, according to the polls, a majority would vote against. After the trial, the final decision to go ahead and implement congestion pricing was taken by local referenda, and then confirmed by the national government in 2007. Only the city of Stockholm could decide in a referendum: congestion pricing was approved by $51 \%$ in favor and $45 \%$ voting against. However, if the neighboring municipalities would have been allowed to vote, it is highly unclear there would have been a majority in favor ${ }^{2}$. The ultimate decision to implement charging was taken in August 2007 by a Liberal-Conservative government, earmarking the revenues to road investments and public transit investments. Winslott-Hiselius et al. (2009) carefully studied public attitudes for the Stockholm trial. He found the same shift in attitudes over time previously observed in other cities: the attitude towards congestion pricing became more favorable during and after the trial, compared to what they were before the trial.

\subsection{Road tolls and the political economy of policy reform: a brief review of the literature}

Of course, resistance to an apparently welfare-enhancing policy reform is not restricted to road pricing. The problem is also well-known in international trade and public finance, and the question why many desirable policies are never implemented has received a lot of attention in the economics literature. Institutional and political failures, uncertainty, and asymmetric information all have been suggested as plausible explanations.

\footnotetext{
${ }^{2}$ Some neighboring municipalities organized similar referenda. Here $40 \%$ were in favor and $60 \%$ voted against. There was no overall majority in favor if all votes (city of Stockholm plus neighboring municipalities) were counted.
} 
First, theories have been developed that explain resistance to policy reform by a political failure that is due to the imperfect monitoring of politicians and the influence of pressure groups (see, e.g., Dixit et al. (1997), Besley and Coate (1999), Coate and Morris (1999)). For example, if associations of road users or trucking companies fear they may be worse off if road pricing is implemented, they may either offer support to politicians for opposing its introduction, or directly lobby against proposals in favor of reform. This will especially be the case if members have made decisions (e.g., with respect to location or modal choice) that were beneficial precisely because of the absence of road pricing (Coate and Morris (1999)). Second, it has been pointed out that resistance to policy reform can be the result of uncertainty. Fernandez and Rodrik (1991) consider a simple model of policy reform in which the aggregate gains and losses of the reform to different groups are known. In a simple majority voting game, they show that status quo bias (i.e., bias against reform) may result when the policy itself makes people switch between groups and, due to individual uncertainty about switching costs between groups, some of the gainers and losers from the reform cannot be identified beforehand. They show that a reform for which a majority would exist once the uncertainty were resolved (ex post) may in fact not be implemented, because individual uncertainty leads a majority of voters to oppose the reform (ex ante). This model seems highly relevant to road pricing, because its introduction will induce a switch from road use to other modes of transport, whereas at the individual level there may be uncertainty as to the willingness to pay for road use of the switching cost to public transport. The Fernandez-Rodrik (1991) model was later extended by Jain and Mukand (2003) in that they allow the government to tax the gainers to compensate the losers. They show that status quo bias persists in the extended model: uncertainty implies that people not only fear to lose from the policy reform; they also fear that, if the next government is dominated by people that gain, no compensation will be paid. Third, resistance to policy reform has been associated with asymmetric information about the level of compensation to be paid to the losing group in the reform (see Mitchell and Miro (2006)). The informational asymmetry induces losers to ask for overcompensation that the winners are not prepared to pay. Sticking to a distortionary policy and not implementing a welfare-enhancing reform then has the 'advantage' that no 
correcting compensations have to be paid: the inefficient policy avoids an informational inefficiency.

The remarkable change in attitudes towards road pricing before and after its introduction has not yet received widespread attention, although a few papers did consider it. Analyzing the Norwegian case, Odeck and Brathen (2002) have hypothesized that it may be related to the improvement in the transport system (using the revenues for transport infrastructure). More recently, Schade and Baum (2006) develop a psychological theory to explain variations in attitudes to road pricing based on cognitive dissonance. They argue that, when there is too much difference between the tolling regime preferred by the individual and the actual regime, individuals adapt their preferences and develop a more positive attitude to urban tolling. They find some support for their theory in a stated preference experiment.

Finally, many transport economists argue that the political support for implementing road pricing is strongly related to who will get the revenues and how these revenues will be used. With respect to the former, King et al. (2006) argue that revenues are best claimed by city centers, so that there is at least one strong advocate for the implementation of road pricing. With respect to the use of the revenues, different proposals have been launched, all involving a substantial share for alternative modes of transport. For example, Small (1992) has suggested that a combination of public transport investments, investment in road improvements and reductions of other taxes may create a sufficiently large majority to allow implementation. Borck and Wrede (2005) consider the potential role of commuting subsidies that allow reducing the demand of rich households for central city housing.

\section{The one-mode model}

In this section, we start with a simple one-mode model. We first introduce the model and discuss the political environment. We then look at the outcomes of the political process for the case without uncertainty. Next we study the economic 
implications of introducing uncertainty for the outcomes of the political process, and we consider the role of experiments in generating a majority in favor of reform.

\subsection{Structure of the model}

We represent the urban area as one homogenous road link that all individuals are interested in using twice a day during the peak period. In this section, the only mode of transport is the private $\mathrm{car}^{3}$. The willingness to pay (WTP) for car use is uniformly distributed so that individuals can be indexed according to their WTP. The individual with highest WTP has index 1, the lowest has index $N$.

We use a simple quasi-linear quadratic utility function with two arguments, road use and all other goods. The latter are priced at marginal cost, and there are no existing taxes. We assume all individuals are risk neutral; we return to issues of risk aversion and loss aversion in the final section of the paper. Let the inverse demand function be given by ( $p$ is price, $n$ the number of car drivers):

$$
p=a-b n
$$

We assume the same value of time for all users. The average time cost is given by the linear relation

$$
A T C=d+c n
$$

where $d$ represents other driving costs and time costs at maximum speed, excluding taxes. ${ }^{4}$ Therefore, the marginal social cost function is

$$
M S C=d+2 c n
$$

As can be seen from this description, we use a partial equilibrium model of the transport market, waving away all other distortions in the transport market and in the rest of the economy (see Parry and Bento (2001), Calthrop, De Borger and Proost (2010)). These distortions exist and affect the choice of the optimal pricing policy, but they are of a second order importance when one considers, as we do in this paper, the behavior of the

\footnotetext{
${ }^{3}$ Note that other types of transport are irrelevant for our purposes as long as they are priced at social marginal cost, and this cost is constant. We will show in the next section that most of the results for the one mode model also carry over to a two-mode model, allowing for public transport subsidies

${ }^{4}$ A linear user cost function can capture a traditional speed-flow model; alternatively, it can be derived from a bottleneck model (Arnott, de Palma and Lindsey (1993)).
} 
voters ${ }^{5}$. Finally, note that in this section we assume lump sum redistribution of the toll revenues. In later sections, we consider public transport subsidies as well.

We use two strong assumptions to stylize political decisions. First, we assume that decisions are taken by simple majority voting. This is important, as it excludes the politician and political institutions as independent agents. In reality, politicians may be particularly important when there is a lot of uncertainty on the outcome of certain policies (see Besley (2006) for a survey). We do not rule out the existence of extra distortions at the level of politicians and agencies; however, they are not modeled here. Second, we only consider two choices for the political system: the status quo without road pricing, and the socially optimal road toll. The reason for focusing on optimal tolling only is that, if we would allow any arbitrary level of tolls and the majority is not driving, the political system may well generate a toll that is much higher than the socially optimal level (see Dunkerley et al. (2009) for an illustration).

Consider the market equilibrium in the absence of socially optimal pricing. The equilibrium number of users $n^{\circ}$ is found by setting price equal to the average user cost, so we have:

$$
n^{0}=\frac{a-d}{b+c}
$$

The social optimum is achieved by pricing at marginal social cost; this implies a lower road use $n^{*}$, viz.:

$$
n^{*}=\frac{a-d}{b+2 c}
$$

The model is illustrated in Figure 1. The social optimum requires setting a tax equal to marginal external cost at the optimal traffic flow. This tax is:

$$
t^{*}=c n^{*},
$$

Toll revenues are then:

$$
t^{*} n^{*}=c\left(n^{*}\right)^{2}
$$

\footnotetext{
${ }^{5}$ In many discussions, environmental concerns are overemphasized as motivation for road pricing. Environmental issues can best be addressed using a combination of a fuel tax and vehicle regulation or taxation.Most estimates of external costs for the US as well as the EU show that external congestion costs are the dominant market failure.
} 
In this section, we assume the revenues are redistributed uniformly to all $N$ consumers (car drivers and others); this means the government can redistribute

$$
\frac{c\left(n^{*}\right)^{2}}{N}
$$

per person. Moreover, for simplicity assume that at a zero price everyone would be driving, so that the total number of individuals (drivers plus others) $N$ equals the number of drivers that would exist at a zero price. Finally, although they can be important for road pricing, we do not take into account transaction costs.
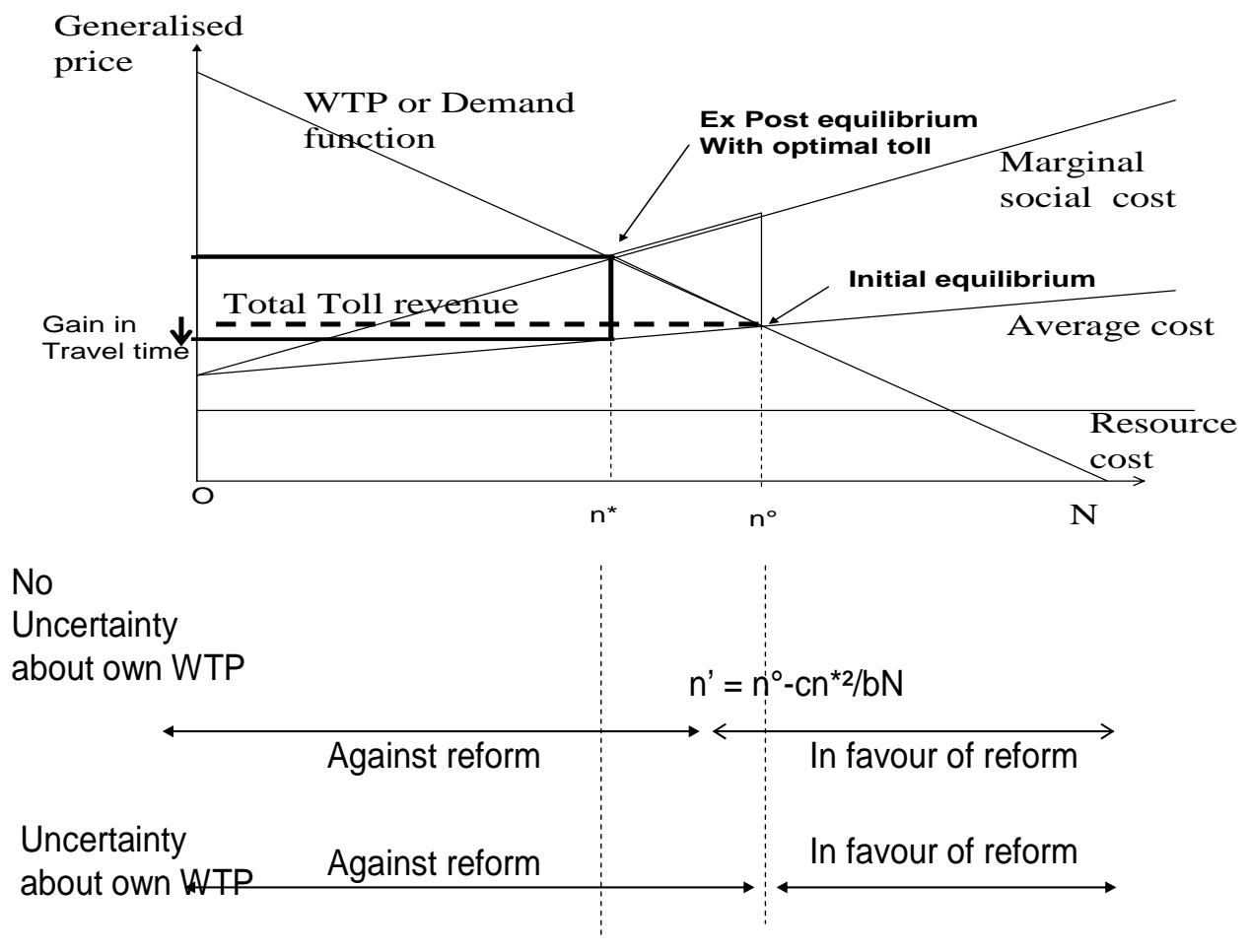

Figure 1. Equilibria with and without an urban toll

\subsection{Decisions under certainty}

Suppose there is no uncertainty; every individual driver knows his willingness to pay. Moreover, every initial driver knows whether or not he will be driving after the introduction of road pricing. 
Consider the introduction of the optimal toll policy with redistribution as described above. First, each person that was initially not a driver (people in the interval $\left.\left(n^{0}, N\right)\right)$ gains the redistributed tax revenues equal to:

$$
\frac{c\left(n^{*}\right)^{2}}{N}
$$

Second, each person that continues to drive after introducing the tax and redistributing the revenues (people in the interval $\left.\left(0, n^{*}\right)\right)$ looses the tax paid, gains some time, and gains the redistributed tax revenues. Total gain per person is

$$
-c n^{*}+c\left(n^{0}-n^{*}\right)+\frac{c\left(n^{*}\right)^{2}}{N}
$$

The first term is the tax paid, the second term is time gain, the third term is the gain from redistribution. It immediately follows that remaining drivers are necessarily worse off. To show this, first note that:

$$
-c n^{*}+c\left(n^{0}-n^{*}\right)+\frac{c\left(n^{*}\right)^{2}}{N}=c n^{0}-c n^{*}\left[2-\frac{n^{*}}{N}\right]
$$

Now use the definitions of $n^{*}, n^{0}$ given above (see (1)-(2)), and note that our model assumptions imply $N=\frac{a}{b}$. Then work out (6) to find:

$$
-c n^{*}+c\left(n^{0}-n^{*}\right)+\frac{c\left(n^{*}\right)^{2}}{N}=-\left[\frac{c(a-d)}{a(b+2 c)^{2}(b+c)}\right][a b c+d b(b+c)]<0
$$

This is necessarily negative, so remaining drivers lose. This may seem counterintuitive, because remaining drivers gain time and they receive part of the revenues collected. However, the time gain is substantially less than the tax paid (see Figure 1), and the tax revenues have to be shared with both initial non-drivers and with all initial drivers that no longer drive.

Third, people that no longer drive because of the tax policy (interval $\left(n^{*}, n^{0}\right)$ ) gain redistributed revenue, they lose the value of the trip (captured by willingness to pay $(a-b n))$, and they gain the average time cost they no longer have to make; this is given by $\left(d+c n^{0}\right)$. Their total gain can be written

$$
-\left[a-b n-\left(d+c n^{0}\right)\right]+\frac{c\left(n^{*}\right)^{2}}{N}
$$


Some ex-drivers will be worse off, some will be better off; this depends on the position of the driver we consider in the relevant interval. People close to $n^{*}$ will be worse off, people close to $n^{0}$ better off $f^{6}$. For the former, the revenues they receive are insufficient to compensate for the loss in value associated with driving; for the latter, the value of the trip only slightly exceeded the time cost, and the revenues received are more than enough to compensate for this loss.

Since the gain is linear in $n$ there exists a cutoff value $n^{\prime}$ such that all people to the left are worse off and everyone to the right is better off. This value is given by solving

$$
-\left[a-b n-\left(d+c n^{0}\right)\right]+\frac{c\left(n^{*}\right)^{2}}{N}=0
$$

for $n$. We find:

$$
n^{\prime}=n^{0}-\frac{c\left(n^{*}\right)^{2}}{b N}
$$

Note that the difference is directly related to the generated tax revenues for redistribution. One further easily shows that $n^{*}<n^{\prime}<n^{0}$.

Consider now a majority vote between the two alternatives considered: no road toll, or a road toll $t^{*}=c n^{*}$ with equal redistribution of the toll revenues to all individuals. Then we have the following result:

PROPOSITION 1. Under certainty, there is a majority for an optimal road toll if $n^{\prime}=n^{0}-\frac{c\left(n^{*}\right)^{2}}{b N}<\frac{N}{2}$.

It is easily shown that $n$ ' is declining in $c$. Consequently, for given $N$, it is easier to get a majority for road pricing when the network is quite congestible.

${ }^{6}$ This can easily be shown. For example, the gain for the driver at $n^{0}$ equals $\frac{c\left(n^{*}\right)^{2}}{N}>0$. Evaluated at $n^{*}$, simple algebra shows (using the definitions of $n^{*}, n^{0}$ ) that the gain is given by $\frac{c n^{0}}{N(b+2 c)^{2}}[-a(3 c+2 b)-d(b+c)]<0$. 
In Figure 1, the first line under the supply and demand figure gives the number of individuals that are in favor and against the optimal urban toll. If $n$ ' is smaller than $N / 2$, there is a simple majority to introduce the optimal urban toll.

\subsection{Decisions under uncertainty (ex ante)}

Now introduce uncertainty. There are several ways to do so. One source of uncertainty is the use of the toll revenues. A citizen may be unlikely to favor a toll when it is not clear how the money will be used: for direct redistribution, for beneficial projects, or for bad projects. In our one-period model, however, without any role for politicians, this is a less interesting avenue. We therefore focus on another source of uncertainty: the idiosyncratic uncertainty of the car user who does not know how easy it is to give up his car use. In the literature on economic reform (see Fernandez and Rodrik (1991) and Jain and Mukand (2003)), the uncertainty of the individual on his cost of adaptation is often used as holding up many industrial and trade reforms. In our model, we assume initial drivers are uncertain as to their exact WTP for car use. This seems not implausible. Many initial drivers may not know for sure whether they will still use their car once pricing is introduced. Specifically, assume initial drivers only know the fraction of drivers that will continue to use their car after the introduction of a road toll, but they do not know their own exact position. As initial drivers, they only know they are situated in the range $\left(0, n^{0}\right)^{7}$.

Suppose initial drivers vote on the basis of the expected gain in the range $\left(0, n^{0}\right)$. This equals:

$$
\frac{n^{*}}{n^{0}}\left[-c n^{*}+c\left(n^{0}-n^{*}\right)+\frac{c\left(n^{*}\right)^{2}}{N}\right]+\left[\frac{n^{0}-n^{*}}{n^{0}}\right]\left\{\frac{c\left(n^{*}\right)^{2}}{N}-\left[a-b\left(\frac{n^{0}+n^{*}}{2}\right)-\left(d+c n^{0}\right)\right]\right\}
$$

The first term is the fraction of continuing drivers times their gain per person. The second term is the fraction of people not driving anymore times the expected gain in the relevant

\footnotetext{
${ }^{7}$ A more realistic assumption is that drivers know whether they have a relatively high or relatively low WTP for car use. This implies that the drivers in the category $\left(n^{*}, n^{\circ}\right)$ would have a less negative expected benefit of the introduction of road pricing. In this case our main results still hold but we need to impose some additional parameter restrictions.
} 
interval $\left(n^{*}, n^{0}\right)$. Since demand is linear, this is obtained by evaluating $n$ at the mean of the interval.

To evaluate the expected gain (10), first note that the last term between square brackets can be worked out to equal:

$$
\left\{\frac{c\left(n^{*}\right)^{2}}{N}-\left[a-b\left(\frac{n^{0}+n^{*}}{2}\right)-\left(d+c n^{0}\right)\right]\right\}=\frac{c\left(n^{*}\right)^{2}}{N}-\frac{b}{2}\left(n^{0}-n^{*}\right)
$$

Substitute in (10) to get:

$$
\frac{n^{*}}{n^{0}}\left[-c n^{*}+c\left(n^{0}-n^{*}\right)+\frac{c\left(n^{*}\right)^{2}}{N}\right]+\left[\frac{n^{0}-n^{*}}{n^{0}}\right]\left[\frac{c\left(n^{*}\right)^{2}}{N}-\frac{b}{2}\left(n^{0}-n^{*}\right)\right]
$$

Simple algebra implies that this expression can be rewritten as

$$
\frac{c n^{*}}{n^{0} N}\left(n^{0} N-2 n^{*} N+n^{0} n^{*}\right)-\frac{b}{2 n^{0}}\left(n^{0}-n^{*}\right)^{2}
$$

Now, using (1), (2) and the definition of $N$, we have

$$
\left(n^{0} N-2 n * N+n^{0} n^{*}\right)=\frac{-b d(a-d)}{b(b+c)(b+2 c)}<0
$$

It follows that (11), and hence (10), is necessarily negative.

We have, therefore, shown that the expected gain for all initial drivers is negative under our assumptions. Consequently, if people vote on the basis of the expected gain under uncertainty, all $n^{0}$ people will vote against.

\subsection{Implications of uncertainty}

The type of idiosyncratic uncertainty introduced above has important implications. It may affect the outcome of the political process of majority voting. Moreover, it raises questions on the role of road pricing experiments that are often suggested to gain more support for road pricing, by reducing uncertainty. In the remainder of this section, we discuss these issues consecutively.

\subsubsection{Conflict between ex ante and ex post political outcomes}

Note that in the absence of uncertainty all voters to the left of $n$ ' vote against. Under uncertainty, all $n^{0}$ people will vote against. We can conclude then that: 
1. Since $n^{1}<n^{0}$, more voters will be against under uncertainty than under certainty.

2. If $n^{\prime}<\frac{N}{2}<n^{0}$ a majority is against under uncertainty, although a majority would have been in favor in the absence of uncertainty.

The difference in voting behavior is illustrated on the bottom part of Figure 1: the uncertainty on the cost of giving up the car generates a larger fraction of the population against urban road tolling. Note that $\frac{N}{2}<n^{0}$ is not a strong condition at all in our setting; it is easily shown that it will necessarily hold as long as the price elasticity of demand at $n^{0}$ is less than one in absolute value.

The possibility that uncertainty may imply a majority against road pricing even though a majority would have been in favor in the absence of uncertainty raises a number of further interesting questions. First, what is the relation between the welfare gain of road pricing and the likelihood of having a majority in favor of the reform under uncertainty? Indeed, uncertainty means that a larger welfare gain of road pricing does not necessarily imply that it is more likely to be actually implemented. Second, how important is the 'conflict range', i.e., the range for which a majority is against ex ante but in favor ex post? In Appendix 1, we show that the answer to both questions crucially depends on the relative slopes of the demand function and the user cost function ( $b$ and $c$, respectively). It is shown that, except for a very price sensitive demand (low value of $b$ ), a higher welfare gain also implies a higher likelihood of getting a majority ex ante. Moreover, it is shown that the conflict range exists for a wide variety of values of $(b / c)$; it reaches a maximum at $b=2 c$.

\subsubsection{Uncertainty and the role of an experiment}

An obvious way to resolve the uncertainty on the cost of adaptation is to conduct a road pricing experiment, as was done in Stockholm. This raises the question whether a majority will vote in favor of having such an experiment?

Consider a rational individual in our simple model who is initially using his car. He is uncertain about his WTP and, as shown above, has a negative expected benefit of the introduction of an urban road toll. It is easy to show that he will also have a negative 
benefit of an experiment on road pricing. As a consequence, if there was ex ante a majority against the toll, there will also be a majority against an experiment.

The proof goes as follows. Consider an individual that has a negative expected benefit as driver, although he would actually benefit from the introduction of road tolling because he is situated in the range $\left(n^{\prime}, n^{0}\right)$ as defined in (8). If he votes in favor of the experiment, he would after the experiment realize that he benefits from road tolling; so would all others in the range $\left(n^{\prime}, n^{0}\right)$. But if he votes in favor of the experiment, then after the experiment there would be a majority in favor of road tolling. The reason is that, together with the individuals in the range $\left(n^{\circ}, N\right)$, the group $\left(n^{\prime}, n^{0}\right)$ then forms a majority in favor of an experiment and, after the experiment, a majority in favor of implementing the road toll. For people in the range $\left(n^{\prime}, n^{0}\right)$, voting in favor of an experiment would, therefore, be equivalent to voting in favor of introducing road tolling. However, these people have, ex ante, a negative expected benefit. Therefore, anticipating the consequences, they will never rationally favor an experiment on road tolling.

We summarize the results of this section in the following proposition.

PROPOSITION 2. When initial car users are ex ante uncertain on their total willingness to pay for car use, there can be ex ante a majority against a road toll and a majority ex post for car use. This happens if $n^{\circ}>N / 2>n$ '. In this case there will also be no majority for a road pricing experiment that reveals the individual WTP of car users.

\section{A two-mode model when not everyone needs transport}

In this section, we extend the model in two ways. First, the $N$ transport users are given the choice between either using their car or using public transport. The introduction of public transport also implies more flexibility in using the revenues of road pricing: they can be reimbursed lump-sum to voters, they can be used to subsidize public transport (or to improve the quality of public transport, which is the same in our model, see below), or a combination of both. Second, we now assume there is a fixed number of $(M-N)$ people that do not use any (peak) transport at all. These include various groups that do 
not work (the retired, the unemployed, discouraged workers, etc.), individuals that use other transport modes (biking, walking), etc.

The setting described may reflect the peak-period transport problem in an urban setting. If the government is thinking about introducing a toll-subsidy package in the city, this affects car and public transport users. Moreover, different allocations of toll revenues are possible which may have implications for voting behavior. Finally, including the group of non-transport users in the peak period is relevant in the sense that these people may be allowed to vote on proposals to introduce road pricing. Depending on the use of the revenues, they may or may not benefit from its introduction. For example, if the policy includes redistribution to all citizens, it also affects those people in urban areas that use neither a car nor public transport during the peak.

\subsection{Formulation of the model}

The model is illustrated using Figure 2. Despite the various extensions, the graphical analysis and the description of the user and social equilibrium only needs slight adaptation compared to the model of the previous section. To see this, let $M$ be the total number of voters. Total transport demand $N$ is assumed to be given; hence, we assume total demand is perfectly inelastic but, of course, modal choice is not. Total demand is divided between car demand $n$ and public transport demand $(N-n)$. People choose between car and public transport based on the overall generalized cost. The average cost for car transport is, as before:

$$
d+c n
$$

The generalized cost of public transport is assumed to be uniformly distributed; it is measured from right to left on Figure 2. It is assumed that people face a different generalized cost of public transport due to, e.g., differences in access cost (related to, e.g.,

proximity to the network). People with the lowest generalized cost of public transport are on the right. The higher the access cost the further people are situated to the left. We capture the generalized cost of public transport for a given individual indexed $n$ by the expression ( $a-b n)$. This cost is the sum of private access and time costs, the time cost associated with the trip itself and, in the absence of public transport subsidies, the marginal resource cost of providing the service. Note that the marginal resource cost can 
be decreasing (due to economies of scale) as long as the private access costs are sufficiently strongly increasing. Figure 2 shows the analogy with the one-mode case: the WTP for car use is now re-interpreted as the generalized access cost for public transport; this cost increases from right to left, starting at 0 in point $N$.

We now assume that all $N$ individuals want to make a trip and have to choose between car and public transport. All people with a generalized cost of public transport exceeding the cost of car use will go by car. To determine the initial equilibrium number of car users, we equate the marginal cost of public transport and the cost of car use. In the absence of taxes and subsidies, the solution to $(d+c n)=(a-b n)$ yields the initial number of car users as:

$$
n^{0}=\frac{a-d}{b+c}
$$

The number of public transport users in the initial situation is $\left(N-n^{0}\right)$.

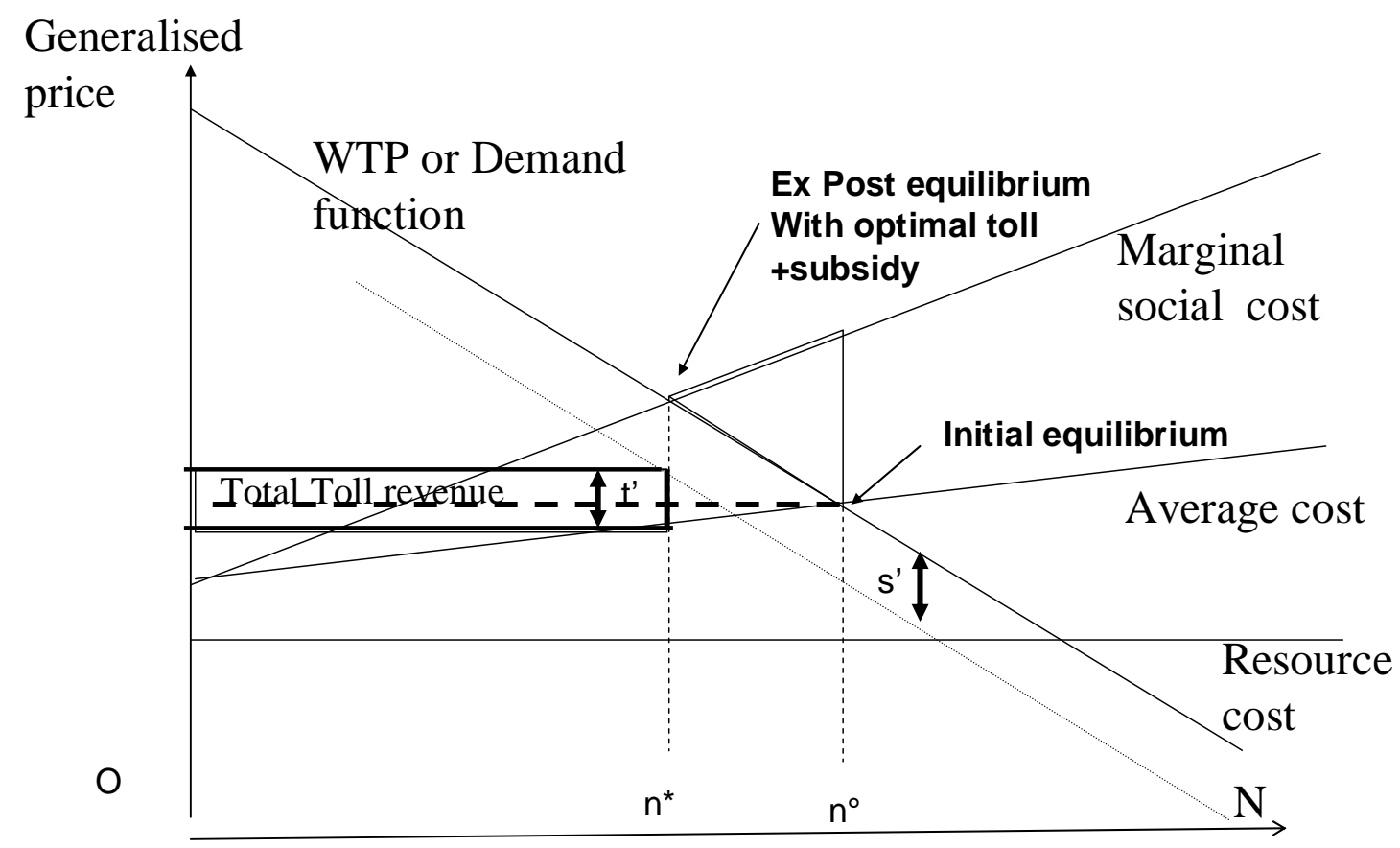

Figure 2: The two mode model 
The welfare optimum in this setting is obtained by minimizing total user costs for all travelers. If the number of car users is $n$, then all car users face a cost $(d+c n)$. The cost for each of the $(N-n)$ public transport users depends on each person's individual generalized cost. Given linearity of the cost function the total cost of all public transport users is given by $(N-n)$ times the average cost of public transport between $n$ and $N$. Hence the optimal equilibrium $n$ solves:

$$
\operatorname{Min}_{n} n(d+c n)+(N-n)[(a-b n)+(a-b N)] \frac{1}{2}
$$

Solving this problem yields the welfare optimal number of car users; it is given by:

$$
n^{*}=\frac{a-d}{b+2 c}
$$

Note that this is the same expression we found in the one-mode setting.

The presence of public transport allows us to consider not only a road toll but also public transport subsidies (as before, the toll is denoted $t$; the subsidy is denoted $s$ ). For a given combination of a toll $t$ and a subsidy $s$, the user equilibrium that determines the number of car and public transport users requires:

$$
a-b n-s=d+c n+t
$$

Using this expression and the equation for $n^{*}$, we find that the tax and subsidy combination that implements the welfare optimum must satisfy:

$$
t+s=c n^{*}
$$

Given the setup of our model, this implies that there are, in principle, an infinite number of tax and subsidy combinations that can be used to implement the welfare-optimal solution. This is due to our assumption of given total transport demand N. Suboptimal pricing of car use complemented with public transport subsidies induces the first best, because total demand is perfectly inelastic.

In what follows, we consider three alternative government policies.

(i) First, the government imposes the optimal tax on road use and does not subsidize public transport. Toll revenues are redistributed to all $M$ people on a per capita basis. In other words, we have

$$
\begin{aligned}
& t=c n^{*}=c\left(\frac{a-d}{b+2 c}\right) \\
& s=0
\end{aligned}
$$


Each person receives $\frac{c\left(n^{*}\right)^{2}}{M}$ in redistributed revenues.

(ii) Second, we consider a situation where toll revenues are used partially for subsidies to public transport and partially for lump-sum redistribution. We look at optimal tax-subsidy combinations (hence, they satisfy $t+s=c n^{*}$ ) and suppose there is no formal government budget restriction. The revenue surplus of the welfare-optimal tax and subsidy package is simply redistributed to all $M$ voters on a per capita basis, where we consider only combinations for which a positive amount is available for lump-sum redistribution. Hence, the taxsubsidy combination satisfies

$$
t+s=c n^{*}=c\left(\frac{a-d}{b+2 c}\right)
$$

Redistribution per person amounts to

$$
\frac{t n^{*}}{M}-\frac{s\left(N-n^{*}\right)}{M}=\frac{(t+s) n^{*}}{M}-s \frac{N}{M}>0
$$

Note that there are an infinite number such $(t, s)$ combinations.

(iii)Third, assume an optimal toll-subsidy combination is introduced (hence, it satisfies $t+s=c n^{*}$ ), where the toll revenues can only be used to subsidize (or be invested in) public transport. In other words, the optimal tax-subsidy combination must satisfy the government budget restriction $t n^{*}-s\left(N-n^{*}\right)=0$. One easily shows that this results in a unique welfareoptimal road tax and subsidy package

$$
t=c n *\left(1-\frac{n^{*}}{N}\right) ; \quad s=\frac{c\left(n^{*}\right)^{2}}{N}
$$

\subsection{Decisions under certainty}

For the different types of people (continuing car drivers, people switching from car to public transport, continuing public transport users, people not demanding any peakperiod transport), we first discuss the effects of each of the three tax policy options 
separately. We then discuss for each group the ranking of four alternative policies, viz. the three road pricing options plus a fourth option which is the status quo, i.e. have no road pricing at all. Finally, we discuss the outcomes of majority voting over the four policy options.

Option (1): optimal tax with simple redistribution

The net gains to each of the different groups were derived in a completely analogous way as in the previous section. The results are given in Table 1 . We find that the net gain to continuing drivers (group $0-n *$ ) is now given by

$$
-c n^{*}+c\left(n^{0}-n^{*}\right)+\frac{c\left(n^{*}\right)^{2}}{M}
$$

which is negative under a very mild condition. Of course, under this option both continuing public transport users $\left(n^{0}-N\right)$ and people not demanding any transport at all $(N-M)$ are better off because they receive part of the revenues. Finally, people that switch from car to public transport $\left(n^{*}-n^{0}\right)$ can be better or worse off. As before, a cutoff value can be determined. We find that everyone to the left of

$$
n^{0}-\frac{c}{b} \frac{\left(n^{*}\right)^{2}}{M}
$$

will be worse off.

\begin{tabular}{|l|l|}
\hline Interval & Net gain \\
\hline $0->n^{*}$ & $-c n^{*}+c\left(n^{0}-n^{*}\right)+\frac{c\left(n^{*}\right)^{2}}{M}$ \\
\hline$n^{*}->n^{0}$ & $-\left[a-b n-\left(d+c n^{0}\right)\right]+\frac{c\left(n^{*}\right)^{2}}{M}$ \\
\hline$n^{0}->N$ & $\frac{c\left(n^{*}\right)^{2}}{M}$ \\
\hline$N->M$ & $\frac{c\left(n^{*}\right)^{2}}{M}$ \\
\hline
\end{tabular}

Table 1: Net gain for option 1 
Option 2: optimal tax-subsidy with redistribution

Similarly, the gains to the different groups for the option in which the revenues of the toll are used for a combination of public transport subsidies and redistribution are summarized in Table 2. Note that redistributed revenues are

$$
\frac{t n^{*}-s\left(N-n^{*}\right)}{M}=\frac{(t+s) n^{*}}{M}-s \frac{N}{M}=\frac{c\left(n^{*}\right)^{2}}{M}-s \frac{N}{M}
$$

For the group that switches from car to public transport $\left(n^{*}->n^{0}\right)$, fewer people will be against the policy as compared to Option 1. The cutoff value for being worse off and hence against the policy is given by

$$
n^{0}-\left[\frac{c\left(n^{*}\right)^{2}}{b M}+s\left(\frac{M-N}{b M}\right)\right]
$$

\begin{tabular}{|l|l|}
\hline Interval & Net gain \\
\hline $0->n^{*}$ & $-c n^{*}+c\left(n^{0}-n^{*}\right)+\frac{c\left(n^{*}\right)^{2}}{M}+s\left(\frac{M-N}{M}\right)$ \\
\hline$n^{*}->n^{0}$ & $-\left[a-b n-\left(d+c n^{0}\right)\right]+\frac{c\left(n^{*}\right)^{2}}{M}+s\left(\frac{M-N}{M}\right)$ \\
\hline$n^{0}->N$ & $\frac{c\left(n^{*}\right)^{2}}{M}+s\left(\frac{M-N}{M}\right)$ \\
\hline$N->M$ & $\frac{c\left(n^{*}\right)^{2}}{M}-s \frac{N}{M}$ \\
\hline
\end{tabular}

\section{Table 2: Net gains for option 2}

Option 3: optimal tax-subsidy with budget restriction

If all toll revenues can only be used to finance public transport subsidies, the net gains are as in Table 3. People that demand no transport at all are unaffected. Note that for the other groups we find exactly the same result as in the case of one mode. 
The gain for continuing car drivers will be negative under a mild condition. That in theory it might be positive can be understood as follows. Intuitively, if there are a large number of continuing car drivers and few public transport users that need to be subsidized, then the tax per car driver will be small. If the congestion function is relatively steep, time savings for car drivers may outweigh the small tax paid. Formally, we can easily show that

$$
-c n^{*}+c\left(n^{0}-n^{*}\right)+\frac{c\left(n^{*}\right)^{2}}{N}<0
$$

is equivalent to

$$
\frac{N-n^{*}}{n^{*}}>\frac{c}{b}
$$

This means that the number of ex post public transport users relative to the number of continuing car drivers must be sufficiently large.

People that switch from car to public transport $\left(n^{*}-n^{0}\right)$ can be better or worse off. However, comparing with the previous options, fewer people will be against the policy as compared to Option 1 . The cutoff is

$$
n^{0}-\frac{c}{b} \frac{\left(n^{*}\right)^{2}}{N}
$$

\begin{tabular}{|l|l|}
\hline Interval & Net gain \\
\hline $0->n^{*}$ & $-c n^{*}+c\left(n^{0}-n^{*}\right)+\frac{c\left(n^{*}\right)^{2}}{N}$ \\
\hline$n^{*}->n^{0}$ & $-\left[a-b n-\left(d+c n^{0}\right)\right]+\frac{c\left(n^{*}\right)^{2}}{N}$ \\
\hline$n^{0}->N$ & $\frac{c\left(n^{*}\right)^{2}}{N}$ \\
\hline$N->M$ & 0 \\
\hline
\end{tabular}

Table 3: net gains for option 3 


\section{Comparing the different options}

We are now in a position to compare, for each group, which of the four available options (three road pricing options 1-2-3, plus the option of doing nothing, denoted option 0 ) is preferred. We bring the results together in Table 4. In the final column, we report the implied ranking of the three options from the viewpoint of each of the groups considered: continuing car drivers, people that switch from car to public transport, continuing rail users, and people not demanding transport. Note that setting $M=N$ yields the results of Section 3.

First, consider continuing drivers. Assuming that all road pricing options make them worse off (if not, they would always vote in favor and road pricing would always have a majority) they prefer option 0 (no road pricing at all) over the three others. Of the remaining options, they prefer option 3 over option 1. Although they do not get any revenues back via redistribution, they pay a lower tax under option 3; moreover, under policy 1 they have to share redistribution of the revenues with people not demanding any transport. It is also obvious that they prefer 2 over 1 . Option 3 can easily be shown be preferred to 2 if we assume, as we did, that a positive amount is available for redistribution. To see this, option 3 is preferred to 2 if:

$$
\frac{c\left(n^{*}\right)^{2}}{M}+s \frac{M-N}{M}<\frac{c\left(n^{*}\right)^{2}}{N}
$$

This can be rewritten

$$
\frac{c\left(n^{*}\right)^{2}}{N}\left(\frac{N}{M}-1\right)+s \frac{M-N}{M}<0
$$

Or alternatively,

$$
\left[s-\frac{c\left(n^{*}\right)^{2}}{N}\right]\left(\frac{M-N}{M}\right)<0
$$

Now let us assume that the tax-subsidy combination considered in option 2 is such that it leaves a positive net amount for pure redistribution. So we have:

$$
\frac{c\left(n^{*}\right)^{2}}{M}-s \frac{N}{M}>0 \rightarrow s-\frac{c\left(n^{*}\right)^{2}}{N}<0
$$


Since $M>N$, this immediately tells us that option 3 is better than option 2. So continuing car drivers have a clear ranking: they like 3 better than 2 better than 1 .

Second, consider the group that switches from road to public transport. They clearly prefer options 2 and 3 (the options with subsidies) over option 1 (the option with only redistribution). Moreover, under our assumptions they are better off with option 2 than with 1: the latter only has redistribution, the former provides a direct subsidy to public transport. The ranking of option 0 , having no road pricing at all, depends on the position of the individual in the range $\left(n^{*}, n^{0}\right)$. People with $n<n^{\prime}$, where $n^{\prime}=n^{0}-\frac{c}{b} \frac{\left(n^{*}\right)^{2}}{N}$ is the cutoff under option 3 , will prefer option 0 over option 3 ; the others in the relevant range prefer option 3 over doing nothing.

Third, we see that continuing public transport users prefer option 3 over 2 over 1 for the same reasons. Finally, people that demand no transport at all -- provided a positive amount is redistributed in option 2 -- will prefer 1 over 2 over 3 . For all people in the range $\left(n^{0}-M\right)$ doing nothing is the worst possible scenario, because in that case they get nothing at all.

A summary and graphical illustration of the rankings of the four alternative by each of the groups of voters is given in Figure 3.

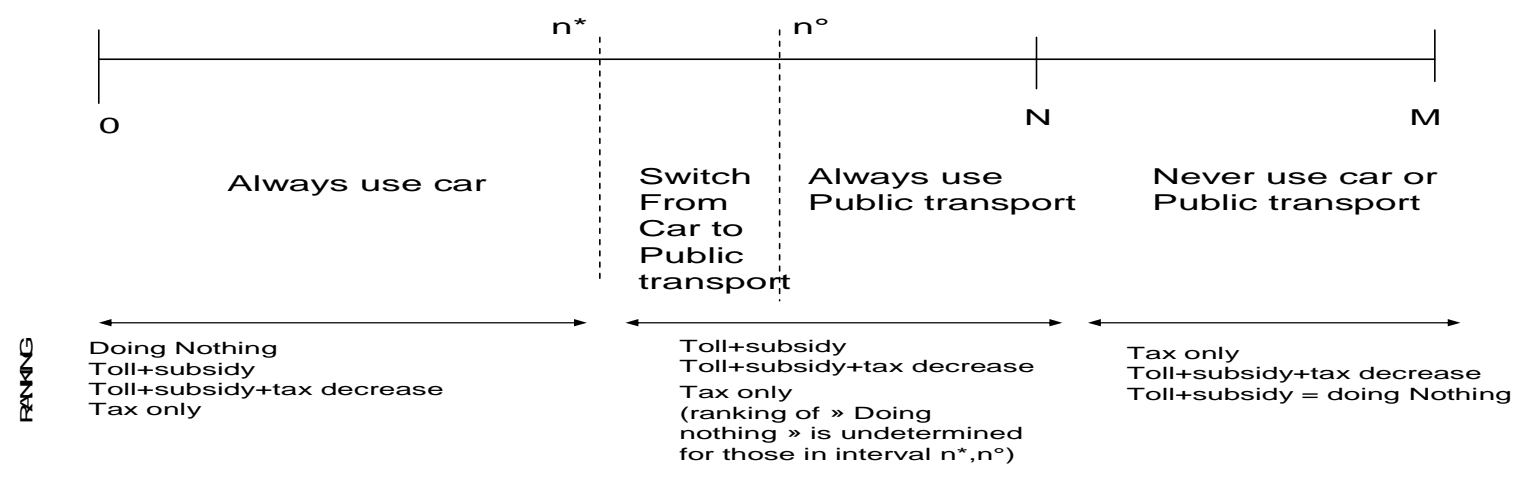

Figure 3. Ranking of alternative reforms in function of willingness to pay of individuals for car use 


\section{Majority voting over alternatives}

We can only guarantee a unique solution for a majority voting system if voting is on a single parameters and we have single peaked preferences. First note that, although we have two policy parameters $(t, s)$ plus redistribution, the choices are implicitly fully described by the choice of one parameter: the tax rate $t$. Indeed, since all road pricing options satisfy $t+s=c n^{*}$, the 4 options to chose from can be written as:

$$
\begin{array}{ll}
\text { Option } 0 & t=0, \\
\text { Option } 1 & t=c n^{*} \text { combined with } s=0 \\
\text { Option } 2 & t>c n^{*}\left(1-\frac{n^{*}}{N}\right) \text { combined with } s<\frac{c\left(n^{*}\right)^{2}}{N} \\
\text { Option 3 } & t=c n^{*}\left(1-\frac{n^{*}}{N}\right) \text { combined with } s=\frac{c\left(n^{*}\right)^{2}}{N},
\end{array}
$$

The description of Option 2 follows from it being all intermediate cases between options 1 and 3. This shows that all options can be formulated in terms of one parameter, the tax t. Using the rankings determined above (see Figure 3 and Table 4), one can easily verify that we have single peakedness of preferences for each of the groups of voters we consider. Moreover, based on the rankings for the different groups, it is straightforward to show Proposition 3. 
PROPOSITION 3. When transport users have the choice between car and public transport but not all voters use transport in the peak period, majority voting over the four alternatives yields the following outcomes:- No road tolling at all has a majority when

$$
n^{\prime}>\frac{M}{2} ; \quad n^{\prime}=n^{0}-\frac{c}{b} \frac{\left(n^{*}\right)^{2}}{N}
$$

- A road toll whose revenues are used only for public transport subsidies is chosen when $n^{\prime}<\frac{M}{2}<N$

- A road toll with full lump sum redistribution and no public transport subsidies is selected when $N<\frac{M}{2}$

In a certain sense, this is bad news; it implies that depending on the number of voters $(M)$ relative to the number of people negatively affected by road pricing $(n ')$ and the total number of travelers in the peak $(N)$ almost anything is possible; to some extent, of course, the number of voters is subject to manipulation (see the Stockholm case mentioned in the introduction, where suburban municipalities were not allowed to vote). A majority will be against road pricing if more than half the number of voters is negatively affected. Tolling and using the revenues to subsidize public transport will get a majority if the previous condition does not hold and total transport users account for more than half the number of voters (provided people not directly affected $(N-M)$ at least get something out of the deal, otherwise they are indifferent ${ }^{8}$ ). Finally, tolling with lump sum redistribution can get a majority if transport users account for less than half the number of people allowed to vote on the proposal. Option 2 never gets a majority.

\footnotetext{
${ }^{8}$ We implicitly assume that the voters in the category $(\mathrm{N}-\mathrm{M})$, when they are indifferent, receive a very small benefit to induce them to participate in the referendum, this could f;i. be an environmental improvement associated to road pricing.
} 


\subsection{Decisions under uncertainty (ex ante)}

What happens under uncertainty? We can go through the analysis as developed before to show that, for each of the three road pricing options, there will be cases where a majority is in favor under certainty, whereas a majority is against under uncertainty. To do so, we give in Table 5, for the three policy options, information on

(a) The cutoff value such that under certainty everyone to the left is against the policy considered. These were derived above.

(b) The expected gain for the initial car users $n^{0}$ under uncertainty. This was calculated as in Section 3 (see, e.g., (10)) for each of the policies considered. For example, for option 1 the expected gain is given by:

$$
\frac{n^{*}}{n^{0}}\left[-c n^{*}+c\left(n^{0}-n^{*}\right)+\frac{c\left(n^{*}\right)^{2}}{M}\right]+\left[\frac{n^{0}-n^{*}}{n^{0}}\right]\left\{\frac{c\left(n^{*}\right)^{2}}{M}-\left[a-b\left(\frac{n^{0}+n^{*}}{2}\right)-\left(d+c n^{0}\right)\right]\right\}
$$

Working out leads to

$$
\frac{c\left(n^{*}\right)^{2}}{M}-\frac{c b n^{*}}{b+2 c}-\frac{b}{2 n^{0}}\left(n^{*}-n^{0}\right)^{2}
$$

This is the result reported in Table 5. A similar procedure is used for the two other options. 


\begin{tabular}{|l|l|l|l|}
\hline & $\begin{array}{l}\text { Option 1 } \\
\text { Road tax with lump } \\
\text { sum redistribution } \\
\text { (no subsidies to } \\
\text { public transport) }\end{array}$ & $\begin{array}{l}\text { Option 2 } \\
\text { Road tax, revenue use for } \\
\text { public transport subsidies } \\
\text { and lump sum redistribution }\end{array}$ & $\begin{array}{l}\text { Option 3 } \\
\text { Road tax used } \\
\text { only for subsidies } \\
\text { to public transport }\end{array}$ \\
\hline $\begin{array}{l}\text { Cutoff value } \\
\text { under certainty } \\
\text { (those to the left } \\
\text { are against } \\
\text { policy) }\end{array}$ & $n^{0}-\frac{c}{b} \frac{\left(n^{*}\right)^{2}}{M}$ & $n^{0}-\left[\frac{c\left(n^{*}\right)^{2}}{b M}+s\left(\frac{M-N}{b M}\right)\right]$ & $n^{0}-\frac{c}{b} \frac{\left(n^{*}\right)^{2}}{N}$ \\
\hline $\begin{array}{l}\text { Expected gain of } \\
\text { initial car drivers } \\
n^{0} \text { under } \\
\text { Uncertainty }\end{array}$ & $\frac{c\left(n^{*}\right)^{2}}{M}-Q$ & $\frac{c\left(n^{*}\right)^{2}}{M}-Q+s\left(\frac{M-N}{M}\right)$ & $\frac{c\left(n^{*}\right)^{2}}{N}-Q$ \\
\hline
\end{tabular}

Note: $Q=\frac{c b n^{*}}{b+2 c}+\frac{b}{2 n^{0}}\left(n^{*}-n^{0}\right)^{2}>0$

\section{Table 5: Comparing the three options with road taxes under uncertainty}

From Table 5, we can extract three pieces of useful information. First, fewer people are against under certainty if the road tax is only used to subsidize public transport (first row of the table shows that the cut-off value of $n$ is smaller for option 3). Second, the expected gain of initial car drivers $n^{0}$ under uncertainty is larger (or a smaller loss in case of a loss) if politicians decide to subsidize public transport (second row of the table shows that highest value is obtained for option 3). Third, assume that the expected gain of initial car drivers is negative in all three cases. Then what can we say about the probability that a different voting outcome would results ex ante versus ex post? To see this, first consider option 1 (tax only). Our findings suggest that we will have a majority in favor of this policy under certainty, but a majority against the policy under uncertainty if

$$
n^{0}-\frac{c}{b} \frac{\left(n^{*}\right)^{2}}{M}<\frac{M}{2}<n^{0}
$$

Similarly, for option 2 the same will happen if

$$
n^{0}-\frac{c}{b} \frac{\left(n^{*}\right)^{2}}{M}-s\left(\frac{M-N}{b M}\right)<\frac{M}{2}<n^{0}
$$


Finally, for option 3 a majority will be pro under certainty whereas a majority will be against due to uncertainty if

$$
n^{0}-\frac{c}{b} \frac{\left(n^{*}\right)^{2}}{N}<\frac{M}{2}<n^{0}
$$

Simple comparison shows that for options 2 and 3 the phenomenon is more likely to occur than under option 1 . So tax policies with some public transport subsidies is more likely to have the problem of majorities against ex ante and majorities pro ex post than policies with only direct redistribution. This gives our last proposition:

PROPOSITION 4. When not all voters use transport in the peak period, there is the highest difference between ex ante and ex post majorities if road pricing is used only for public transport subsidies

A final point on time consistency. Once road pricing has been introduced, the drivers in the category $\left(n^{*}, n^{\circ}\right)$ will have switched to public transit. They know their WTP for car use, uncertainty has been resolved and there is no majority for a return tot the pre-road pricing equilibrium.

\section{Conclusions and caveats}

In this paper, a simple majority voting model was studied in which people vote over the introduction of peak-period road pricing; the model considered two transport modes, car transport and public transport. The revenues of road pricing could be returned lump sum to voters, or they could be used to support public transport.

The model provides an explanation for several observed phenomena associated with the introduction of road pricing in practice; the London and Stockholm experiences serve as relevant cases. The model offers a potential explanation for the empirical observation that the introduction of road pricing in these cities was combined with substantial investment and subsidies in public transport. Introducing idiosyncratic individual uncertainty about the willingness-to-pay for car use, it also explains the evolution of public attitudes towards road pricing that was observed: there was 
widespread opposition to road pricing before its introduction, but public support grew over time after road pricing was introduced. Our model shows that uncertainty may imply the presence of a majority that is ex ante against road pricing and ex post in favor. Finally, we show that the ex ante majority against road pricing also implies that there is no majority for organizing an experiment that would take away the individual uncertainty. This may explain the organization of experiments by the authorities against the will of the population; this was observed, among others, in Stockholm.

Our model was deliberately simple, and a number of strong assumptions were introduced, including equal values of time for all road users, linear congestion functionthe absence of risk and loss aversion, no interaction between car and public transport in the production of congestion, a linear public transport cost function and a uniform distribution of WTP's. It is clear that relaxing these assumptions complicates the analysis, but there are good reasons to believe that the main message of this paper will still hold. First, risk aversion would serve to strengthen the conclusion that ex ante majorities against road pricing may turn into majorities in favor of road pricing ex post. Second, loss aversion (in the sense of status quo bias) among initial drivers reduces the shift from car use to public transport; its main effect in the framework of our model is to make demand for car travel less elastic. Third, allowing car use to affect the time cost of public transport is likely to make public transport more attractive after introducing road pricing, but it also affects the optimal road toll. However, it does not affect the logic of the current paper.

A number of extensions may be worthwhile for future work. For example, the behavior of politicians was completely absent from our model: people voted over the introduction of road pricing, but politicians' preferences and possible lobbying by groups affected by road pricing played no role at all. Finally, other types of uncertainty could be studied, such as uncertainty about the use of the revenues, or uncertainty about the effect of road tolls on traffic levels. 


\section{REFERENCES}

Arnott, R., De Palma, A. and R. Lindsey (1993), A structural model of peak period congestion: a traffic bottleneck with elastic demand, American Economic Review 83, 161179.

Besley T., (2006), Principled Agents, Oxford University Press

Borck R., M. Wrede (2005), Political economy of commuting subsidies, Journal of Urban Economics 57, 478-99

Calthrop E., De Borger B. and S. Proost (2010). Cost-benefit analysis of transport investments in distorted economies. Transportation Res. Part B, forthcoming

Ciccone, Antonio (2004). Resistance to Reform: Status Quo Bias in the Presence of Individual Specific Uncertainty: Comment, American Economic Review 94 (3), 785-795.

Coate, Stephen et Stephen Morris, (1999). Policy Persistence, American Economic Review, 89(5), 1327-1336.

Dixit, Avinash, Gene M. Grossman, and Elhanan Helpman (1997) “Common agency and coordination: General theory and application to government policy making.” Journal of Political Economy, 104(4): 752-769

Dunkerley, Fay, Amihai Glazer, Stef Proost,(2010), What drives gasoline taxes, DP CESKULeuven, http://www.econ.kuleuven.be/eng/ew/discussionpapers/Dps10/DPS1001.pdf

Fernandez, Raquel et Dani Rodrik, (1991). Resistance to Reform: Status Quo Bias in the Presence of Individual-Specific Uncertainty, American Economic Review, 81(5), 114655.

Jaensirisak, S., Wardman, M., May, A.D., 2005. Explaining variations in public acceptability of road pricing schemes. Journal of Transport Economics and Policy 39 (2), 127-153.

Jain, Sanjay et Sharun Mukand, (2003). Redistributive Promises and the Adoption of Economic Reform, American Economic Review, 94(1), 256-264.

Jones, P.M., 2003. Acceptability of road user charging: meeting the challenge. In: Schade, J., Schlag, B. (Eds.), Acceptability of Transport Pricing Strategies. Elsevier, Oxford, pp. 27-62.

David King, Michael Manville, Donald Shoup (2007), The political calculus of congestion pricing, Transport Policy 14 (2007) 111-123 
Larsen, O.I., 1988. The toll ring in Bergen, Norway - the first year of operation. Traffic Engineering and Control 29, 216-222.

Mitchell M., M.Moro, 2006, Persistent distortionary policies, American economic Review, Vol. 96 (1), 387-393

Odeck, J., Brathen, S., 2002. Toll financing in Norway: the success, the failures and perspectives for the future. Transport Policy 9 (3), 253-260.

Parry, I. and A.Bento (2001), Revenue recycling and the welfare effects of road pricing, Scandinavian Journal of Economics, 103(4), 645-671

Prud'homme, Rémy and Juan Pablo Bocarejo,(2005), The London congestion charge: a tentative economic appraisal, Transport Policy, Volume 12, Issue 3, 279-287

Raux, C., Souche, S., 2003. An analytical framework of pricing acceptability: application to four case studies. In: Schade, J., Schlag, B. (Eds.), Acceptability of Transport Pricing Strategies. Elsevier, Oxford, pp. 153-168.

Schade, J., Schlag, B. (Eds.), 2003a. Acceptability of Transport Pricing Strategies. elsevier, Oxford

Transport for London, 2004. Central London Congestion Charging Scheme: Six Months on. Transport for London, London.

Tretvik, T., 2003. Urban road pricing in Norway: public acceptability and travel behaviour. In: Schade, J., Schlag, B. (Eds.), Acceptability of Transport Pricing Strategies. Elsevier, Oxford, pp. 77-92. 


\section{Appendix 1. Implications of different political outcomes ex ante versus ex post}

The possibility that uncertainty may imply a majority against road pricing even though a majority would have been in favor in the absence of uncertainty raises two further issues, discussed below.

\section{How large is the 'conflict' range?}

The relative range $R$ where a conflict arises between the political outcome ex ante and ex post is implicitly given by:

$$
R=\frac{n^{0}-n^{\prime}}{N}
$$

To analyze the determinants of this range, note that we have, after simple algebra:

$$
\begin{aligned}
& \frac{n^{0}}{N}=\left(\frac{a-d}{a}\right)\left(\frac{z}{1+z}\right) \\
& \frac{n^{\prime}}{N}=\left(\frac{a-d}{a}\right)\left(\frac{z}{1+z}\right)-\left(\frac{a-d}{a}\right)^{2}\left(\frac{z}{(2+z)^{2}}\right)
\end{aligned}
$$

where $z=\frac{b}{c}$. This expresses the conflict range as function of the relative slopes of demand and congestion functions. It is then easily shown that the relevant range is at its maximum when $z=2$, or $b=2 c$.

Consider a numerical example. Let $a=10, d=2$, so that:

$$
\frac{n^{0}}{N}=0.8\left(\frac{Z}{1+z}\right)
$$

This is rising in $z$. It equals 0.5 for $z \cong 1.7$. So for $z>1.7$ there is a majority against ex ante. Similarly,

$$
\frac{n^{\prime}}{N}=0.8\left(\frac{z}{1+z}\right)-0.64\left(\frac{z}{(2+z)^{2}}\right)
$$

This is rising in $z$ for all relevant values. It equals 0.5 for $z \cong 2.4$. Hence, for $z<2.4$ there is a majority in favor ex post. The conflict range involves values for $\mathrm{z}$ such that $1.7<z<2.4$. For example, if:

$$
N=100, b=0.1, c=0.05
$$

we find 


$$
n^{0}=53, n^{*}=40, n^{\prime}=45
$$

Under uncertainty, 53\% are against although, under certainty, 55\% would have been in favor.

\section{The welfare gain of road pricing and the probability of implementation}

Does a higher welfare gain imply that the probability of implementation (majority in favor under uncertainty) rises, or is this not guaranteed? To investigate this issue, note that the welfare gain per person can be written as, see Figure 2:

$$
\frac{W G}{N}=\frac{1}{N} \frac{1}{2}\left(n^{0}-n^{*}\right) c n^{0}
$$

Using the definitions of $N, n^{0}, n^{*}$ and simple algebra, this can be rewritten as:

$$
\frac{W G}{N}=\frac{(a-d)^{2}}{2 a}\left[\frac{z}{(1+z)^{2}(2+z)}\right]
$$

Differentiation shows that the gain per person is rising in $a$ and declining in $d$. Moreover, we have:

$$
\frac{\partial\left(\frac{W G}{N}\right)}{\partial z}>0 \Leftrightarrow\left(1-z-z^{2}\right)>0
$$

It follows:

$$
\begin{aligned}
& \frac{\partial\left(\frac{W G}{N}\right)}{\partial z}>0 \text { iff } z=\frac{b}{c}<\frac{1}{2}(\sqrt{5}-1) \cong 0.6 \\
& \frac{\partial\left(\frac{W G}{N}\right)}{\partial z}<0 \text { iff } z=\frac{b}{c}>\frac{1}{2}(\sqrt{5}-1) \cong 0.6
\end{aligned}
$$

Loosely speaking, this means (given the definition of $z$ ) that more congestibility (a higher $c$ relative to $b$ ) raises the welfare gain per person if $z>0.6$.

Next, note that we have a majority under uncertainty if $n^{0}<\frac{N}{2}$. Using the definitions, this can be reformulated as

$$
L<\frac{1}{2} ; \quad L=\frac{(a-d)}{a} \frac{z}{1+z}
$$


It is more difficult to get a majority for higher $a$ and lower $d$. Moreover, $\frac{\partial L}{\partial z}>0$, so that it is always 'more difficult' (in the sense that it becomes more difficult to satisfy $L<0.5$ ) to get a majority if $z$ increases. More congestibility (higher $c$ ) makes it easier to get a majority, because you have fewer drivers.

Therefore, in most cases (as long as $b>0.6 c$ ), a higher welfare gain also implies a higher probability of getting a majority under uncertainty. 


\begin{tabular}{|c|c|c|c|c|}
\hline Interval & Option (1) & Option (2) & Option (3) & Ranking ( $\left.{ }^{\circ}\right)$ \\
\hline $0->n^{*}$ & $-c n^{*}+c\left(n^{0}-n^{*}\right)+\frac{c\left(n^{*}\right)^{2}}{M}$ & $-c n^{*}+c\left(n^{0}-n^{*}\right)+\frac{c\left(n^{*}\right)^{2}}{M}+s\left(\frac{M-N}{M}\right)$ & $-c n^{*}+c\left(n^{0}-n^{*}\right)+\frac{c\left(n^{*}\right)^{2}}{N}$ & $\begin{array}{lll}0 & 3 & 2\end{array}$ \\
\hline$n^{*}->n^{0}$ & $-\left[a-b n-\left(d+c n^{0}\right)\right]+\frac{c\left(n^{*}\right)^{2}}{M}$ & $-\left[a-b n-\left(d+c n^{0}\right)\right]+\frac{c\left(n^{*}\right)^{2}}{M}+s\left(\frac{M-N}{M}\right)$ & $-\left[a-b n-\left(d+c n^{0}\right)\right]+\frac{c\left(n^{*}\right)^{2}}{N}$ & $\begin{array}{l}3 \quad 2 \quad 1 \\
0 \quad \text { better or } \\
\text { worse than } 3\end{array}$ \\
\hline$n^{0}->N$ & $\frac{c\left(n^{*}\right)^{2}}{M}$ & $\frac{c\left(n^{*}\right)^{2}}{M}+s\left(\frac{M-N}{M}\right)$ & $\frac{c\left(n^{*}\right)^{2}}{N}$ & $\begin{array}{llll}3 & 2 & 1 & 0\end{array}$ \\
\hline$N->M$ & $\frac{c\left(n^{*}\right)^{2}}{M}$ & $\frac{c\left(n^{*}\right)^{2}}{M}-s \frac{N}{M}$ & 0 & $\begin{array}{lll}1 & 2 & 3=0\end{array}$ \\
\hline
\end{tabular}

\section{Table 4: Comparison and ranking of the gains for different options}

$\left(^{\circ}\right)$ Option 0 is no road pricing at all. The rankings assume that continuing drivers prefer no road pricing at all over any of the road pricing options. Moreover, it is assumed that under option 2 a positive amount is available for pure redistribution. If not, all people in the range $\mathrm{n}^{*}$-N would prefer 2 over 3. 